\title{
Bringing Rain to the Land: Rainfall Simulation as a Participatory Teaching Aid to Understanding Erosion
}

\author{
C. K. Birkett ${ }^{1}$, T. Hill1ㅅ, K. D. Zuma ${ }^{2}$, T. M. Everson ${ }^{3}$ \\ ${ }^{1}$ Discipline of Geography, School of Agricultural, Earth and Environmental Sciences, University of KwaZulu-Natal, Pietermaritzburg, \\ South Africa \\ ${ }^{2}$ Department of Anthropology and Development Studies, University of Johannesburg, Johannesburg, South Africa \\ ${ }^{3}$ School of Biological Sciences, University of KwaZulu-Natal, Pietermaritzburg, South Africa
}

Email: hillt@ukzn.ac.za

How to cite this paper: Birkett, C.K., Hill, T., Zuma, K.D. and Everson, T.M. (2016) Bringing Rain to the Land: Rainfall Simulation as a Participatory Teaching Aid to Understanding Erosion. Journal of Environmental Protection, 7, 1305-1316. http://dx.doi.org/10.4236/jep.2016.710114

Received: May 11, 2016

Accepted: September 23, 2016

Published: September 26, 2016

Copyright $\odot 2016$ by authors and Scientific Research Publishing Inc. This work is licensed under the Creative Commons Attribution International License (CC BY 4.0).

http://creativecommons.org/licenses/by/4.0/

(c) (i) Open Access

\begin{abstract}
There is a need for science and community knowledge and resources to be combined in the mitigation and rehabilitation of land degradation, as a large portion of degraded land in South Africa is communal land. Rainfall simulation was used at Okhombe valley, KwaZulu-Natal, South Africa as a tool to collect scientific data regarding the erosion rates on cattle access paths and to demonstrate erosion driving forces to the community members. The community members were able to experience erosion taking place through rainfall simulation and observe the impact of slope and basal cover change on erosion rates. Cattle access paths and rehabilitated access paths showed similar runoff rates (Figure 1), however the sediment concentration varied between the severely degraded cattle access paths and the rehabilitated land. Through the rainfall demonstration a better understanding of the driving factors in the erosion process, an understanding of why particular mitigation techniques work and where such mitigation measures would be effective were identified. With the combination of scientific techniques and community knowledge and resources a step can be taken towards sustainable land degradation mitigation and rehabilitation in the communal areas of South Africa.
\end{abstract}

\section{Keywords}

Rainfall Simulation, Okhombe, Community Participation, South Africa, Erosion

\section{Introduction}

Soil erosion is a major global issue that has been described as a process of detachment 


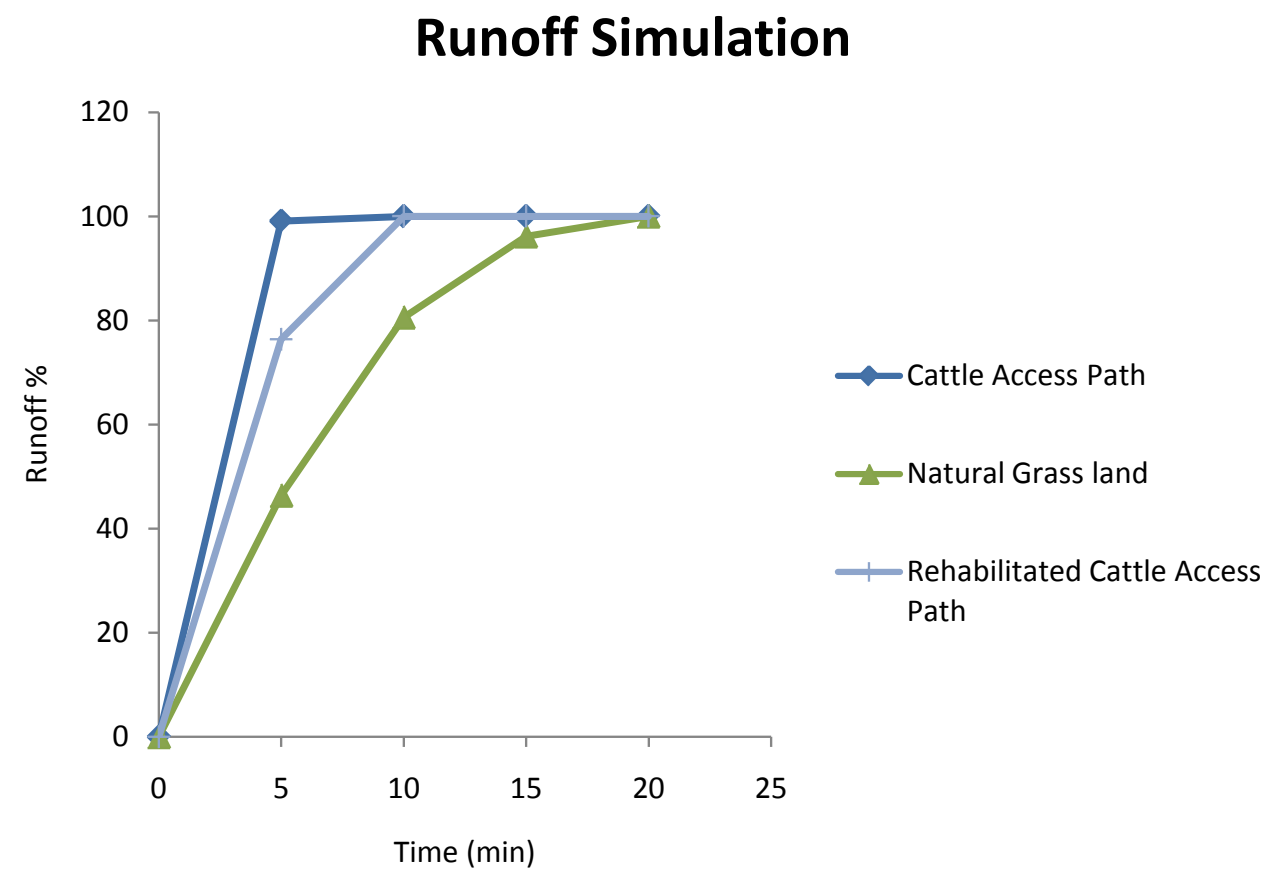

Figure 1. Average runoff rates across runoff plots placed on cattle access paths, rehabilitated access paths and natural grassland.

and transportation of soil material by erosive agents [1]. Although erosion is a natural process due to human influences the rate of erosion can be accelerated beyond the natural rate, which has a major impact on the land, such as loss of fertile soil, loss of grazing or arable land, water storage, sedimentation and water security. All of which have dire consequences for an already fragile food security, in particular within rural marginal regions. It is estimated that approximately $70 \%$ of South Africa's land surface has been affected by degradation [2]. This estimate highlights the magnitude of the land degradation problem in South Africa and emphasises the need to mitigate against continued accelerated land degradation. A large portion of this degraded land is on tribal or communal lands, which are heavily utilized for livestock grazing.

This study aims to link and bridge the gap between scientific knowledge and communal local knowledge on the issue of land degradation in communal areas with a specific focus on cattle access path erosion through rainfall simulation.

According to [3], communal land is severely affected by high populations, increased number of livestock, increased runoff, poor water infiltration, loss of grass cover, severe soil erosion and poor land use management. They cover approximately $13 \%$ of the total agricultural land in South Africa, whilst $37 \%$ of this total is considered as degraded [4]. Thus, it is critical that a sound management strategy be implemented on a land use that plays such an important role in community livelihoods. Within this complex sociopolitical-economical system cognisance must be taken of the reality that livestock, and in particular cattle, are a symbol of wealth and play a major role in the culture of the residents of the communal areas [5]. Therefore, in any management plan, one needs to consider not only the physical impact of livestock on the land but also the socio- 
economic consequences of any pro-active land management measures that involve livestock.

The cattle graze in two zones in the communal areas, in summer the cattle are moved from the households to the grazing land on the higher ground surrounding the villages and in winter the cattle are kept in the lower areas to graze in agriculture fields on crop residue [6]. The daily movement of cattle onto the plateaus of the hills surrounding the homestead, is predominantly due to security concerns with cattle theft being both a perceived and real threat in the region. This constant diurnal migration from the higher regions back and forth along the steep escarpments to the lower lying residential region has led to the generation of deeply incised cattle paths [6]. Furthermore, the same route is generally used each day and one path quickly becomes incised into the landscape, resulting in loss of vegetation cover, increased erosion of the bare soil and surface flow during the severe summer thunderstorms, which dominate the summer months and provide much of the annual rainfall, and exposing the underlying regolith [7]. Once these paths become too deep and impassable the cattle are driven along a parallel, less denuded, route, thus extending the degradation across the steep slopes.

Furthermore, the cattle paths interfere with the natural movement of water down the slope, which is critical in a region that experiences event-driven severe summer thunderstorms. On a slope with no cattle paths the water flowing over the surface will flow as a sheet, this provides the water a large area to infiltrate the soil. Whereas, on a slope with cattle paths, the water will flow as a sheet up to the cattle path and then follow the path down to the foot of the slope, reducing the area for infiltration and increasing the velocity of the water due to the smooth nature of the cattle paths.

The control of land degradation in communal areas is difficult to implement due either to cultural and financial constraints, or the lack of understanding of the processes present in the landscape driving land degradation. All are aware of the consequences and, for many in particular, those living below the steep eroded slopes the effect is all too evident in the form of deep incised gullies and sediment wash from the slopes onto the fields, roads and homesteads. The understanding of the processes driving land degradation is fundamental in the sustainable mitigation of land degradation. Land degradation techniques are often implemented in communal areas where workshops and participatory "field days" are run to engage with community members regarding various techniques such as stone lines and planting vegetation in an attempt to stabilise and minimalize the erosion and hopefully lead to rehabilitation of the site. Once the workshop is over the community members are expected to identify degradation problem in the landscape or potential problems and implement the appropriate mitigation technique. However one aspect missing from the workshops is the fundamental understand of the degradation process and driving factors, this is very difficult to explain as the principals are often abstract in nature. The lack of understanding results in incorrect mitigation measure being implemented or mitigation measure only being implemented when degradation reaches an irreversible state.

Erosion by the very nature of the complex variables influencing the rates is site spe- 
cific and to mitigate or control erosion rates these complex variables need to be studied at a site scale. The catchment scale research does play a role in mitigation however when projects are aimed at particular site rehabilitation and mitigation, the driving factors need to be studied in-depth. Models can be used to study erosion and further understand the rates of degradation occurring in a particular area. Another method of studying erosional processes at a site scale is rainfall simulation. Rainfall simulation is an effective technique which can be used as a substitute for rain, and has been used by researchers since the mid-1930s, in which infiltration, runoff, sediment yield and erosion can be measured and integrated to environmental biotic factors such as; surface roughness, slope angle, and vegetation cover [8]. There are often time constraints and issues with rainfall seasonality, thus making rainfall simulation useful and the intensity of the simulated rainfall can be controlled unlike in natural rainfall events. A key advantage of rainfall simulation is the visualisation of erosion processes created by the simulation and the ability to alter either rainfall factors such as intensity, duration and type and/or environmental factors such as slope angle, vegetation cover or soil type, to allow for observation and understanding.

\section{Study Site}

The Okhombevalley is situated in the northern Drakensberg escarpment, close to the town Bergville, in the province of KwaZulu-Natal, South Africa (Figure 2).

The Okhomberural community is predominantly subsistence farmers with small gardens surrounding their homesteads and livestock which graze on the plateaus of the surrounding hills. The area not only is home to rural communities who utilize the landscape for grazing and crop production but also forms a part of the water catchment area for the Tugela Vaal Water Scheme which is vital for a secure water source for the country's industrial regions. This particular area has received assistance in the past few years with regard to management and conservation of the communal land, with the government initiating the land care programme in 1999 [9]. The programme was a job creation initiative which focused on the degraded areas in the communal land and introduced erosion control measures implementable by the community members [3]. The programme was a success but one criticism was the lack of quantitative information on how much of a success the erosion control methods were [9]. The next to implement a programme was the Water Research Commission (WRC), focused on empowering the community to take charge of the rehabilitation, monitoring and management of the communal area. The project was successful with visible changes in the rehabilitated areas and better land management [9]. Through this approach the community was provided information on the importance of conservation and management of the communal land to ensure security of their livelihoods. The rehabilitation, monitoring and management are on-going.

\section{Methods}

A workshop demonstrating the use of a rainfall simulator and on-site experimentation 


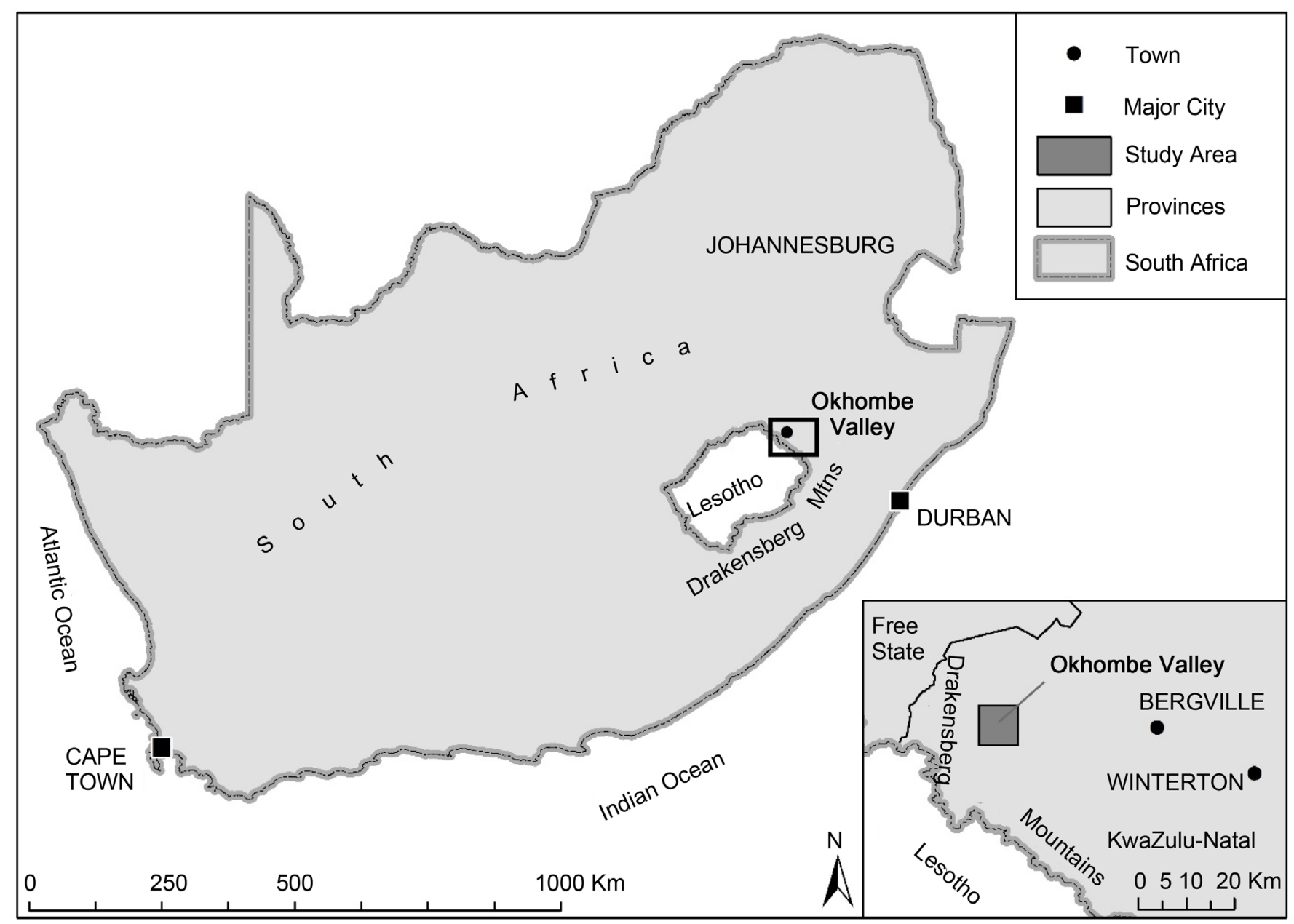

Figure 2. Location of the Okhombe Valley, South Africa.

where implemented to inform community members of the severity and impact of land use management on soil erosion on cattle access paths. The rainfall simulations were used as a demonstration tool in the workshop to demonstrate the primary driving factors of land degradation.

Rainfall simulation trials were carried out on cattle access paths, rehabilitated paths and what is described as "natural" grassland, all within the same micro-catchment and on comparable slopes. The methods for the rainfall simulation was very specific with importance placed on calibration, for consistency and protocol to accurately record erosion rates for specific rainfall intensities and allow for comparability between simulations, trials and sites [10].

Two separate calibrations were carried out; one with the plot level to the ground to determine consistent flow rates and a second with the plot at the angle of the slope to determine flow rates on varying slope angles as evident on the access paths. This was undertaken to accurately determine the rate of "artificial" rainfall being applied to the slope as there are many factors that can influence the rainfall rate. The plot was calibrated at the horizontal to the correct rainfall rate to replicate a particular rainfall rate 
on the slope. The two rainfall intensities used for the simulations was $30 \mathrm{~mm} / \mathrm{h}$ and 60 $\mathrm{mm} / \mathrm{h}$, described by [11] as the average and extreme values for rainfall in the area. The second calibration was to correct for the slope and as less rainfall would fall on the plot, due to the reduction in surface area, which needed to be accounted for when determining the infiltration rates and runoff rates.

The simulations were run for 10 minutes to wet the soil and then stopped for 10 minutes to create an air gap between the infiltrating water and the soil surface [10]. During the 10 minute break a $100 \%$ runoff plot was placed over the $1 \mathrm{~m}^{2}$ runoff plots to determine the exact intensity of the rain simulation. The simulator was run for $1 \mathrm{~min}$ ute and all runoff collected to determine the intensity over time. After the 10 minute break, the simulation was started and ran for 20 minutes. After the first 20 minute simulation the simulator was stopped and the intensity rechecked on the $100 \%$ runoff plot placed over the $1 \mathrm{~m}^{2}$ runoff plot. Twenty-four hours later the simulator was re-run at a higher intensity following the same procedure as the first simulation. The simulations were run on cattle access paths, natural grassland and rehabilitated access paths with the intention of understanding erosion rates and identifying the effectiveness of community implemented rehabilitation measures on the landscape. In conjunction with the scientific research that took place, community involvement was of paramount importance as the community members had been involved in land degradation mitigation and prevention through the various programmes implemented in the area.

\section{Results}

The results are presented as two separate but integrated sections; the results from the workshop and the rainfall simulations conducted on the cattle access paths, rehabilitated access paths and natural grassland.

The community workshop was held at the local school attended by approximately 60 community members, including local leadership, government officials and community herdsman. The workshop explored the community's experiences with land degradation and how it has affected their lives. The community explained some of the issues with regards to erosion, how it had effected their lives and what measures the community had attempted to control land degradation. The community went on to explain the success of the implemented measures and how the community needs to do more to reduce the level of land degradation in the area.

The second step in the workshop was to run the simulation for the community members to observe what the researches were doing in the area and second to explain some of the driving factors of the erosion process to the community members. The final step in the community workshop was to re-engage with the community regarding the land degradation problem in the area to consider that after thinking about the driving factors their perception of the issue had changed. The community members were asked to help highlight, on an aerial photograph of the area, where the land degradation issues were of greatest concern and why those regions in particular.

The results from the rainfall simulation (Table 1 and Table 2) show runoff values in 
Table 1. Runoff percentage and sediment $\left(\mathrm{g} \cdot \mathrm{l}^{-1}\right)$ from runoff plots placed on cattle access paths.

\begin{tabular}{|c|c|c|c|c|c|c|c|}
\hline \multicolumn{8}{|c|}{ Cattle Access Path } \\
\hline \multicolumn{3}{|c|}{ Inhibition (\%) } & \multicolumn{3}{|c|}{ Simulation (\%) } & \multicolumn{2}{|c|}{ Sediment $\mathrm{g} \cdot \mathrm{l}^{-1}$} \\
\hline Time & I1 & I4 & Time & $\mathrm{R} 1\left(27 \mathrm{~mm} \cdot \mathrm{h}^{-1}\right)$ & $\mathrm{R} 4\left(80 \mathrm{~mm} \cdot \mathrm{h}^{-1}\right)$ & R1 & R4 \\
\hline $2: 30$ & 51.15 & 0 & 5 & 99.08 & 75.4 & 3.05 & 3.29 \\
\hline 5 & 100 & 0 & 10 & 100 & 76.3 & 3.37 & 11.87 \\
\hline $7: 30$ & 100 & 17.29 & 15 & 100 & 87.5 & 3.56 & 4.57 \\
\hline 10 & 100 & 47.49 & 20 & 100 & 84.85 & 3.05 & 16.33 \\
\hline
\end{tabular}

Table 2. Runoff percentage and sediment $\left(\mathrm{g} \cdot \mathrm{l}^{-1}\right)$ from runoff plots placed on rehabilitated cattle access paths.

\begin{tabular}{ccccccccc}
\hline \multicolumn{7}{c}{ Rehabilitated Cattle Access Path } \\
\hline \multicolumn{7}{c}{ Inhibition (\%) } & \multicolumn{5}{c}{ Simulation (\%) } & \multicolumn{2}{c}{ Sediment $\mathbf{~} \mathbf{l}^{-1}$} \\
\hline Time & I7 & I11 & Time & R7 $\left(\mathbf{4 2} \mathbf{m m} \cdot \mathrm{h}^{-1}\right)$ & R11 $\left(56 \mathbf{m m} \cdot \mathrm{h}^{-1}\right)$ & R7 & R11 \\
\hline $2: 30$ & 15.8 & 0 & 5 & 76.37 & 90.68 & 1.32 & 1.22 \\
5 & 100 & 0 & 10 & 100 & 100 & 1.43 & 1.23 \\
$7: 30$ & 100 & 57.35 & 15 & 100 & 100 & 1.64 & 1.26 \\
10 & 100 & 91.92 & 20 & 100 & 100 & 1.64 & 1.12 \\
\hline
\end{tabular}

percentage for simulations run on the cattle access paths and rehabilitated cattle access paths with the sediment load in the runoff collected $\left(\mathrm{g} \cdot \mathrm{l}^{-1}\right)$. Each simulation $(\mathrm{R})$ had an inhibition rainfall simulation (I) conducted prior to commencement of the rainfall simulation (R).

\section{Discussion}

\subsection{Community Knowledge}

The community workshop held was very successful, there was a large turnout and the community members were eager to discuss the issues of land degradation. After a brief discussion on the land degradation issue in the community and the mitigation measure that are being implemented the rainfall simulation was run for the community members to see. The pre-rainfall simulation discussion was to provide a brief overview of the issue of land degradation in the community area from the perspective of the community members. The community members explained where they thought land degradation was an issue in the area and the community members went on further to explain the mitigation and rehabilitation techniques that had been utilized.

\subsection{Rainfall Simulation}

The rainfall simulation worked well as a spatial tool for visually demonstrating the processes of erosion and the driving forces. The first simulation was set-up prior to the community arriving for the workshop on a plot with low basal cover. With the com- 
munity members around the simulator the first simulation was run. Almost instantly runoff began with a high sediment concentration. Concepts such as raindrop induced detachment and transportation was explained to the community members. The community members entered into long discussions around the processes and where in their community area they had witnessed or evidence of transportation and detachment was. During the rainfall simulation demonstration the erosion processes and driving factors were explained to the community members. The community members could ask questions and point in the plot to where erosion was taking place. Immediately discussion arose as to what would happen if the plot was moved to a steeper slope or a slope with less vegetation. The advantage of the small plot size means the simulation can easily be moved to various areas land use types to demonstrate different factors. The plot was moved to a more vegetated slope to demonstrate to the community how good basal cover can assist in mitigation the rate of degradation. The community members were interested to see the change from a bare plot to a vegetated plot. The simulation was run again and the community observed and commented on the difference between the two simulations. The runoff on the second plot took a bit longer to begin indicating infiltration was taking place. This was explained to the community members. The runoff contained far less sediment yield than the previous simulation on the bare ground. The concept of interception and reduced surface flow velocity due to vegetative cover was examined.

From the change in plot position a discussion arose from the community members with regards the mitigation and rehabilitation techniques they had been implementing. The community members discussed how they now understand why they need to put in the mitigation measures as they now understand the driving factors behind the erosion. The discussion after the second simulation was useful as community members discussed the mitigation measure they had been utilizing and where various measures would be more successful than other places due to the driving forces of land degradation they had just witnessed. Work on land degradation has been going on for many years in the region and the feedback from the workshop was that now the community members better understand what causes the erosion in their area.

After witnessing and discussing the simulations and erosion demonstration one community member raised an observation with regards removal of alien vegetation from the catchment which is an on-going social up-liftmen program [12]. The community member noted that often where alien vegetation had been removed gullies had begun to form and land degradation accelerated. From watching the simulations on vegetated and on bare ground the community member had come to the realisation that the removal of the alien invasive species had accelerated the land degradation due to the loss of vegetative cover. Further to this the community member inquired if there were other species of plant which could be grown in the areas where the alien vegetation had been removed to reduce the rate of degradation. The community had observed that iLothane (Buddleja salvifolia) grew in the areas that had severe form of land degradation and that these species aided the binding of soil and reduction of soil losses. 


\subsection{Land Degradation on a Broader Scale}

From the discussion and simulations the community members were shown aerial photographs of the area and asked to identify land degradation issues. The community members pointed out all the cattle access paths and how now after the simulation they can see the problem with moving the cattle up steep slopes and issues surrounding overgrazing.

\subsection{Mitigation}

The findings above present a difficult situation to develop a mitigation plan. The community members can see the change in erosion rates from vegetated to non-vegetated sites and steep verse gentle slopes however the livestock need to graze and to access the grazing land on top of the plateaus steep slopes must be traversed. The use of the steep slopes results in the formation of cattle paths with low basal cover which accelerates the rate of land degradation. One solution was to fence the cattle paths off to prevent cattle movement, however the cattle move around the fence creating another degradation issue along the side of the previous degradation problem [3].

The runoff results (Table 1 and Table 2) from the simulations carried out in the Okhombe valley on cattle access paths and rehabilitated sites suggest a similarity in runoff experienced on the cattle path verse the rehabilitated site. The runoff starts at a similar time after the beginning of the simulation and quickly increases to $100 \%$ runoff. The soil analysis of the soils surrounding the runoff plots described the soil as clay having a clay content greater than $60 \%$. The high clay content in the soil could be the reason for the low infiltration and high runoff rates documented during the rainfall simulations.

The sediment concentration (Table 1 and Table 2) are lower for the rehabilitated cattle access path as opposed to the cattle access path, where the concentration on the rehabilitated path is less than $2 \mathrm{~g} \cdot \mathrm{l}^{-1}$ and the concentration on the rehabilitated site varies from $3 \mathrm{~g} \cdot \mathrm{l}^{-1}$ to $16 \mathrm{~g} \cdot \mathrm{l}^{-1}$. The rehabilitated site has approximately $100 \%$ basal cover whereas the cattle path has $0 \%-5 \%$ basal cover. The basal cover is the primary reason for the difference between the sediment concentrations as the vegetation will help to bind the soil, slow down surface runoff and intercept raindrops to reduce raindrop induced detachment.

The results from the rainfall simulations show how susceptible and sensitive the area is to land degradation. The runoff rates are high due to the soil properties, any disturbance in terms of vegetative cover (overgrazing or trampling) or channelling from cattle access paths will result in some form of land degradation. This makes mitigation of land degradation through controlled grazing and access paths a complex issue.

The social, cultural and economic value of livestock to the community is high and this needs to be considered in any management plan. The cattle need to graze on the plateaus however any movement up the slopes can result in erosion paths. One potential mitigation measure that could be considered is path design with reference to paths designed in the Drakensberg reserve for soil erosion control on hiking trails and con- 
trolling the movements of the cattle to specifically designed paths.

\subsection{Rainfall Simulation as a Tool}

Rainfall simulations can be used as a comparison with other similar sized plots and simulation protocol. The data collected are plot specific and so comparisons can be made between different areas. To use the rainfall simulator for comparison studies it is imperative that the same method protocol be implemented and correct calibration is carried out. Another consideration is the equipment needed to run a successful rainfall simulation is bulky and difficult to move easily. A few assistants are needed to move the equipment around from plot to plot. The site needs to be fairly accessible by vehicle to help transport the equipment.

The erosion rates quantified by means of rainfall simulation are site specific and unique to that particular runoff plot. The advantage of this is the ability to run comparative tests or experiments in a micro-environment, where various erosion mitigation measures effectiveness can be tested. This was the case in the Okhombe where rainfall simulation was used to establish a baseline erosion rate to compare rehabilitation techniques. The simulation affords to the scientist the ability to establish standardised quantitative information regarding erosion rates for comparison with other runoff plots with different parameters. [13] utilised rainfall simulation to determine certain factors for the USLE equation as it was expensive and difficult to obtain natural erosion rates from rainfall events.

One advantage of rainfall simulation is a visual demonstration of erosional processes. The rainfall simulation can be used as a demonstration as well as scientific quantification of erosion rates. This tool was used with great success in the Okhombe community as community members were able to observe the impacts vegetation cover had on erosion rates and rainfall intensity and slope gradient. Furthermore, the simulation provided a good opportunity to initiate a dialogue with community members with regards to soil erosion processes. Its visual and its real and one can easily alter some set parameters to demonstrate impact. However, the simulation as a tool for quantifying and understanding erosion rates does have some limitations, such as plot size, calibration, and water use. These limitations must be understood and integrated into the community demonstration and on-site field work. By way of example, a single rainfall simulation experiment uses approximately 400 litres of water that has to be collected from a nearby clean source (using river/dam water could clog mechanics and level of macroand micro-nutrients would be high and need to be measured prior to the experiment). In a water scare region one must take cognisance and be sensitive to water usage, hence for our workshop we re-used the water during the demonstrations and collected all unused water and clean water for the community to use.

\section{Conclusions}

Land degradation is a major global issue threatening arable land, grazing, food security and water security. Approximately $70 \%$ of South Africa has been affected by land deg- 
radation, emphasising the need to understand land degradation drivers and implement correct, appropriate mitigation and rehabilitation techniques. It is imperative that the land degradation found in communal areas is mitigated or rehabilitated as a large portion of the degraded land is communal areas which are necessary for sustained livelihoods. There needs to be a combination of scientific techniques and studies combined with local knowledge and resources available to community members to mitigate and rehabilitate land degradation in communal areas.

It is often difficult to explain scientific knowledge to community members, rainfall simulation provides a tool that can be used for both scientific data collection and a demonstrative tool of erosion processes to community members. The rainfall simulation was used in the Okhombe valley to study cattle path erosion and in a workshop held in the area for the community members. The community members quickly gained the concepts of slope gradient and basal cover from the rainfall demonstrations. The community could see the outcome of low basal cover and steep slope gradient verse high basal cover and gentle slope gradient. The community then began to understand why mitigation measures worked and to identify sites where various mitigation techniques would work more effectively than other techniques. The understanding of the driving factors of land degradation provides the community with an applied understanding of the problem faced by the area and renewed energy and ideas to combat land degradation.

\section{Acknowledgements}

This paper emanated from a Water Research Commission Project (K5/2402) entitled: "Assessing the impact of erosion and sediment yield from different land uses in farming and forestry systems and their effect on water resources in selected catchments of South Africa”. Their support and funding are acknowledged and thank you. The Okhombe community played an integral part of the knowledge acquisition and allowing the research to take place in their community.

\section{References}

[1] Ellison, W.D. (1947) Soil Erosion Studies-Part I, Agricultural Engineering, 28, 145-146.

[2] Le Roux, J.J., Newsby, T.S. and Sumner, P.D. (2007) Monitoring Soil Erosion in South Africa at Regional Scale: Review and Recommendations. South African Journal of Science, 103, 329-335.

[3] Hoffman, T.M. and Todd, S. (2000) A National Review of Land Degradation in South Africa: The Influence of Biophysical and Socio-Economic Factors. Journal of South African Studies, 26, 743-758. http://dx.doi.org/10.1080/713683611

[4] Wessels, K., Prince, S., Frost, P. and Van Zyl, D. (2004) Assessing the Effects of Human-Induced Land Degradation in the Former Homelands of Northern South Africa with a $1 \mathrm{~km}$ AVHRR NDVI Time-Series. Remote Sensing of Environment, 91, 47-67.

[5] Cousins, B. (1999) Invisible Capital: The Contribution of Communal Rangelands to Rural Livelihoods in South Africa. Development Southern Africa, 16, 299-318.

[6] Peden, M.I. (2009) Tackling “The Most Avoided Issue”: Communal Rangeland Manage- 
ment in Kwazulu-Natal, South Africa. African Journal of Range and Forage Science, 22, 167-175.

http://dx.doi.org/10.2989/10220110509485876

[7] Goméz, J.A. and Nearing, M.A. (2005) Runoff and Sediment Losses from Rough and Smooth Soil Surfaces in a Laboratory Experiment. Catena, 59, 253-266. http://dx.doi.org/10.1016/j.catena.2004.09.008

[8] Frasier, G.W., Weltz, M. and Weltz, L. (1998) Technical Note: Rainfall Simulator Runoff Hydrograph Analysis. Journal of Range Management, 51, 531-535.

http://dx.doi.org/10.2307/4003370

[9] Everson, T.M., Everson, C.S. Zuma, K.D. (2007) Community Based Research on the Inflence of Rehabilitation Techniques on the Management of Degraded Catchments. Report to the Water Research Comission. Report Number 1316/1/07, August 2007.

[10] Podwojewski, P., Janeau, J,J., Grellier, S., Valentin, C., Lorentz, S. and Chaplot, V. (2010) Inflence of Grass Soil Cover on Water Runoff and Soil Detatchment under Rainfall Simulation in a Sub-Humid South African Degraded Rangeland. Earth Surface Processes and Landforms, 36, 911-922. http://dx.doi.org/10.1002/esp.2121

[11] Nel, W. and Sumner, P.D. (2007) Intensity, Energy and Erosivity Attributes of Rainstorms in the KwaZulu-Natal Drakensberg, South Africa. South African Journal of Science, 103, 398-402.

[12] Le Maitre, D.C., van Wilgen, B.W., Gelderblom, C.M., Bailey, C., Chapman, R.A. and Nel, J.A. (2002) Invasive Alien Trees and Water Resources in South Africa: Case Studies of the Costs and Benefits of Management. Forest Ecology and Management, 160, 143-159. http://dx.doi.org/10.1016/S0378-1127(01)00474-1

[13] Kose, C. (1998) Determining of P Factor for Contour Tillage Using Simulator under Field Condition in Aegean Region. Unpublished Ph.D. Thesis, Department of Soil, Ege University, Izmir.

Submit or recommend next manuscript to SCIRP and we will provide best service for you:

Accepting pre-submission inquiries through Email, Facebook, LinkedIn, Twitter, etc. A wide selection of journals (inclusive of 9 subjects, more than 200 journals)

Providing 24-hour high-quality service

User-friendly online submission system

Fair and swift peer-review system

Efficient typesetting and proofreading procedure

Display of the result of downloads and visits, as well as the number of cited articles Maximum dissemination of your research work

Submit your manuscript at: http://papersubmission.scirp.org/

Or contact jep@scirp.org 